\title{
UMA REFLEXÃO SOBRE A IMPORTÂNCIA DO CICLO DE VIDA DO PRODUTO APLICADA À ENGENHARIA DO PRODUTO
}

Gleice Kelli de Alcântara Anastácio, Larissa Brito Santos de Aguiar, Pedro Paulo Liberato Gomes, Andréia de Menezes Olivo.

Universidade do Oeste Paulista - Unoeste, Faculdade de Engenharia Conselheiro Algacyr Munhoz Maéder, Curso de Engenharia de Produção, Presidente Prudente - SP. E-mail: gleice kelli10@hotmail.com.

\section{RESUMO}

O presente artigo aborda como tema a engenharia do produto, que é a área da Engenharia de Produção responsável pelo projeto, planejamento e desenvolvimento de um produto, além de adaptações e melhorias do mesmo. Nesta área, destaca-se como assunto principal o ciclo de vida do produto, que é definido como a trajetória de um produto desde sua criação e lançamento até sua retirada do mercado. Através de uma abordagem qualitativa, da aplicação do método comparativo e da utilização da pesquisa bibliográfica como técnica de coleta de dados, o artigo tem como objetivo promover uma reflexão sobre a importância de analisar o comportamento e a influência das variáveis relacionadas ao ciclo de vida de um produto durante o desenvolvimento deste. $\mathrm{O}$ artigo visa também apresentar e discutir a capacidade de associar os produtos aos seus respectivos estágios, além de compreender e evidenciar quais são os fatores determinantes para o sucesso em cada fase e o que se pode fazer para evitar o declínio e alcançar o prolongamento do ciclo de vida.

Palavras-chave: planejamento, projeto e desenvolvimento do produto; ciclo de vida do produto; estratégia; inovação.

\section{A REFLECTION ABOUT THE IMPORTANCE OF THE PRODUCT LIFE CYCLE APPLIED TO THE PRODUCT ENGINEERING}

\begin{abstract}
This article discusses the theme of the product engineering, which is the area of Production Engineering responsible for the design, planning and development of a product, and adaptations and improvements thereof. In this area stands out as main subject the product life cycle, which is defined as the path of a product since its creation and launch until its withdrawal from the market. Through a qualitative approach, the application of the comparative method and the use of bibliographic research as a data collection technique, the article aims to promote a reflection on the importance of analyzing the behavior and influence of variables related to the life cycle of a product during its development. The article also aims to introduce and discuss the ability to associate products to their respective stages, and understand and demonstrate what are the determining factors for success at each stage and what you can do to prevent the decline and achieve the extension of life cycle.
\end{abstract}

Keywords: planning, design and product development; product life cycle; strategy; innovation. 


\section{INTRODUÇÃO}

Segundo a Associação Brasileira de Engenharia de Produção (ABEPRO, 2008), a engenharia do produto é o conjunto de ferramentas e processos de projeto, planejamento, organização, decisão e execução direcionado às atividades estratégicas e operacionais de desenvolvimento de novos produtos. A engenharia do produto pode ainda ser conceituada a partir da definição de Chiavenato (2014, p. 58), na qual "[...] dá-se o nome de desenvolvimento de produtos/serviços à área que cuida de todos os estudos e pesquisas sobre criação, adaptação, melhorias e aprimoramento dos produtos/serviços [...]".

No que se refere ao assunto, o presente artigo aborda o ciclo de vida do produto, que está imerso na engenharia do produto, podendo ser considerado uma sub-área, pois as ferramentas e conhecimentos da área principal são aplicáveis ao mesmo. De acordo com Naveiro (2008, p. 138), o ciclo de vida do produto é definido como o "[...] histórico do produto desde sua criação até sua retirada do mercado".

Ao longo de sua vida, os produtos geralmente passam por quatro estágios: a introdução, caracterizada pelo lançamento do produto e percepção do mesmo pelo mercado; o crescimento, que se trata da ascensão das vendas e maior conhecimento do produto; a maturidade, que se caracteriza pela estabilização das vendas; e o declínio, em que há decréscimo das vendas, sendo esta a fase mais delicada, pois pode extinguir o produto definitivamente. (NAVEIRO, 2008)

É perceptível que muitas empresas têm ido à falência por não adquirirem a capacidade de renovação do ciclo de vida de seus produtos, estagnando o processo de produção e as estratégias. O desenvolvimento de novos produtos deve estar estritamente vinculado à inovação tecnológica, pois esse fator é determinante para a permanência competitiva no mercado. A falta de atualização de uma empresa pode ser a causa de seus crescentes prejuízos e de sua consequente saída do mercado. Entretanto, variáveis como a qualidade do produto, a flexibilidade, velocidade e confiabilidade de atendimento e satisfação do consumidor, a administração dos custos e recursos e a própria concorrência podem contribuir para o declínio precoce de um produto.

Mas quais são os reais fatores determinantes em cada estágio do ciclo de vida de um produto e qual deve ser o posicionamento para evitar o declínio e manter a competitividade no mercado? A partir da discussão realizada neste artigo, utilizando a abordagem qualitativa e o método comparativo, e com o auxílio da literatura existente sobre o assunto, pretende-se alcançar a resposta para as questões propostas e atingir o objetivo de compreender o conceito de ciclo de vida do produto e possibilitar o seu prolongamento.

\section{CICLO DE VIDA DO PRODUTO}

Segundo Naveiro (2008, p. 138), "denomina-se ciclo de vida de um produto ao histórico do produto desde sua criação até a sua retirada do mercado." Para Moreira (2014, p. 207), "o ciclo de vida é apenas um modelo, útil, porém impreciso [...]. Por meio desse modelo, podemos associar a um dado produto cada uma das fases da demanda e estudar as implicações da fase para os esforços de Marketing e de Produção." Kotler e Keller (2006) afirmam que o conceito de ciclo de vida do produto possui utilidade na análise de uma categoria de produto, da forma de um produto, do produto em si ou de uma marca.

Segundo Kotler e Keller (2006), a estratégia da organização quanto ao posicionamento e diferenciação deve mudar ao longo do ciclo de vida de seus produtos, de modo a acompanhar as alterações do mercado, da concorrência, e também a evolução do próprio produto. Ao dizer que um produto possui um ciclo de vida faz-se necessário aceitar os seguintes fatores: os produtos possuem vida limitada; as vendas dos produtos passam por estágios distintos, cada um deles com desafios, oportunidades e problemas diferentes; os lucros oscilam nos diferentes estágios; os produtos necessitam de diferentes estratégias em todos os setores funcionais da organização de acordo com cada estágio do seu ciclo de vida. 


\section{Estágios do ciclo de vida de um produto}

Kotler e Armstrong (2015) afirmam que o ciclo de vida do produto apresenta quatro estágios principais, além de considerarem o desenvolvimento do produto como um estágio inicial, conforme a representação da Figura 1, que exemplifica a trajetória das vendas a partir da curva tradicional do ciclo de vida de um produto, e também os lucros obtidos ao longo de cada estágio.

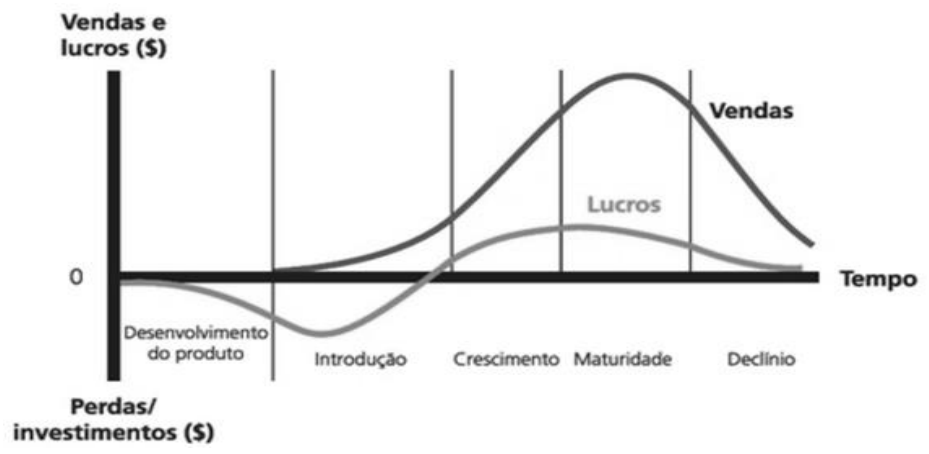

Figura 1. Vendas e lucros ao longo da vida do produto Fonte: Kotler e Armstrong (2015, p. 298).

O primeiro estágio do ciclo de vida de um produto é a introdução. De acordo com Moreira (2014), neste estágio o produto começa a ser fabricado e é lançado no mercado. Devido ao fato de o mercado não estar familiarizado com o produto, a demanda é razoavelmente baixa, a maioria dos consumidores pode estar aguardando uma oportunidade de consumo viável, como a queda do preço e/ou o aperfeiçoamento do produto. Martins e Laugeni (2002) afirmam que a introdução é caracterizada por um baixo volume de vendas e de produção, pedidos sob encomenda e sob medida e produção em pequenos lotes.

Do ponto de vista de um engenheiro de produção, a produção em pequena escala é adotada visto que se trata de uma fase de teste e possivelmente correções e adaptações serão necessárias para atender as necessidades do mercado e convertê-las em produtos inovadores, garantindo assim a sua aceitação e os consequentes lucros nos estágios posteriores.

O estágio seguinte é o crescimento, que segundo Moreira (2014), é o momento no qual o produto começa a se tornar competitivo e a publicidade contribui para o seu conhecimento no mercado. Martins e Laugeni (2002) afirmam que devido ao aumento de demanda, na fase de crescimento, a empresa busca trabalhar com um maior volume de produção através da padronização de componentes, automatização dos processos produtivos e investimento na fabricação para estoque.

Como se pode imaginar, é necessário que um produto proporcione satisfação ao mercado para que ocorra a sua expansão neste meio. Uma ideia inovadora tende a atrair a atenção da concorrência devido à oportunidade de lucros. Diante desta situação, a construção de estoques é uma interessante estratégia para se destacar entre a concorrência, visto que permite uma maior velocidade e confiabilidade de atendimento ao consumidor. Na maioria dos processos produtivos, o custo unitário de produção é reduzido consideravelmente a partir de um grande volume de demanda, possibilitando assim que a organização se dedique a maximizar a qualidade do produto ou a ofertar novos modelos.

O terceiro estágio do ciclo de vida do produto é a maturidade, Moreira (2014) afirma que neste estágio o produto já está bem integrado no mercado e se inicia a estabilização das vendas. Nesta fase, o produto deve apresentar uma qualidade e confiabilidade totalmente satisfatória. Naveiro (2008) argumenta que neste estágio a empresa deve se concentrar na simplificação do processo produtivo, de modo a reduzir o custo final do produto, aumentar a produtividade e manter a competitividade. De acordo com Martins e Laugeni (2002), neste estágio geralmente o produto já possui um alto grau de padronização, o que contribui com a redução dos custos. 
É fato que com uma grande oferta do mesmo produto e a saturação de atendimento ao mercado, ocorre uma estagnação do volume de vendas. Os concorrentes, a fim de permanecerem competitivos, tendem a reduzir seus preços e aumentar sua propaganda. Porém, os que não obtêm êxito com este posicionamento começam a se retirar do mercado, e com o tempo, o setor acaba dominado pelas empresas bem estabelecidas.

Kotler e Armstrong (2015) ressaltam que os produtos que permanecem na fase de maturidade há muito tempo estão em constante evolução para conseguir atender às necessidades dos consumidores, que mudam com o passar do tempo. Os engenheiros de produção devem não só defender ou acompanhar o produto que está há muito tempo no mercado, mas também considerar uma modificação no mercado, na oferta do produto e no mix de marketing.

É possível afirmar que a modificação do mercado consiste na busca por novos públicos consumidores. A modificação do produto, por sua vez, é baseada na alteração de características funcionais e visuais do produto. Por fim, a empresa pode modificar seu mix de marketing, melhorando as vendas a partir de novas estratégias publicitárias, aperfeiçoamentos e promoções.

Finalmente, o último estágio é denominado declínio, no qual, segundo Moreira (2014), o produto começa a perder espaço no mercado, se tornando obsoleto, e como consequência, há um decréscimo significativo da demanda. De acordo com Kotler e Armstrong (2015), esta é a fase final da vida do produto, é o momento em que se vê a necessidade de eliminá-lo definitivamente, ao vendê-lo para outra empresa ou ao liquidá-lo a um preço irrisório; de reduzir os custos destinados ao produto, aumentando assim a margem de lucro; ou ainda de modificar radicalmente o projeto com o intuito de voltar ao estágio de crescimento.

De acordo com Kotler e Keller (2006), na fase de declínio, as estratégias adotadas devem incluir a redução dos preços e a descontinuação de produtos fracos, a seleção dos pontos de vendas lucrativos e o abandono dos não lucrativos, e a redução dos investimentos em propaganda a um nível suficiente para manter os consumidores fidelizados. Ou, em contrapartida, a empresa pode optar pelo aumento dos investimentos com o intuito de dominar o mercado ou fortalecer sua competitividade ao se remodelar e continuar atendendo às necessidades do consumidor.

É perceptível que algumas das razões para o declínio são os rápidos avanços tecnológicos, o aumento e destaque da concorrência e as alterações das necessidades do consumidor. Sendo assim, é necessário que a empresa invista em uma constante atualização para se manter sempre a frente em seu segmento de mercado e satisfazer o seu público-alvo.

Kotler e Keller (2006) destacam que nem todos os produtos seguem a curva tradicional do ciclo de vida, podendo aderir a outros três padrões comuns, conforme mostra a Figura 2.
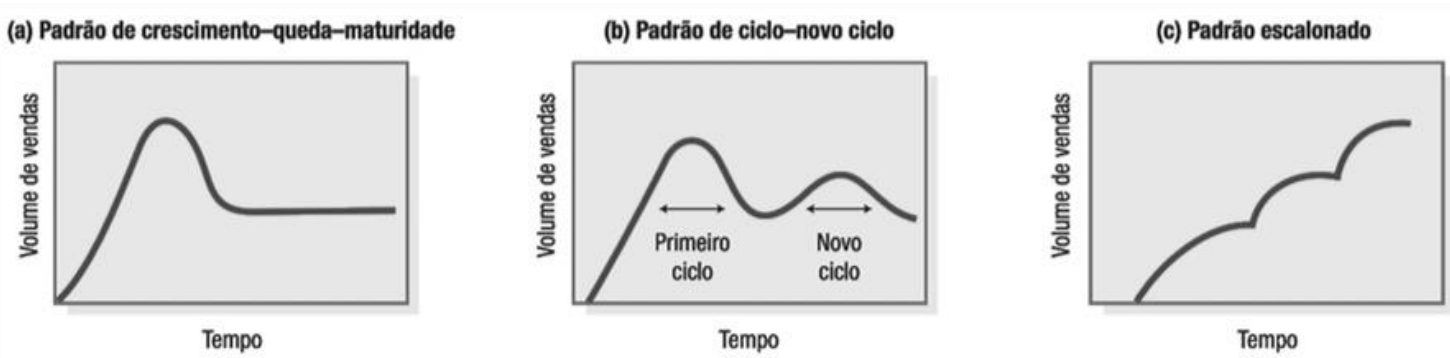

Figura 2. Padrões comuns de ciclo de vida do produto Fonte: Kotler e Keller (2006, p. 317).

Na Figura 2 (a) é apresentado o padrão de crescimento-queda-maturidade, no qual as vendas se elevam rapidamente ainda na fase de introdução e em seguida se estabilizam, atendendo consumidores retardatários ou aqueles que adquiriram o produto no início e precisam substituí-lo. (KOTLER; KELLER, 2006) 
Observa-se que este padrão representa um produto que foi bem integrado ao mercado e que após o seu lançamento e crescimento de suas vendas atingiu um patamar de estabilização na maturidade, necessitando apenas de adaptações conforme o surgimento de novas tecnologias.

Há também o padrão de ciclo-novo ciclo, representado na Figura 2 (b). Neste modelo, há uma promoção agressiva do novo produto, originando o primeiro ciclo. Posteriormente, há declínio nas vendas e como estratégia a empresa lança uma nova campanha, gerando um novo ciclo, que geralmente possui impacto e duração menores que o primeiro. (KOTLER; KELLER, 2006)

Neste caso, percebe-se que a demanda do produto oscila constantemente devido ao desinteresse por parte do público consumidor após um determinado período, exigindo que a organização promova frequentes relançamentos para que as vendas voltem a crescer. Esta situação pode ser resultado de uma pesquisa de mercado ineficiente, que impede a estabilidade do produto no mercado.

Outro padrão apresentado por Kotler e Keller (2006) é o escalonado, conforme a Figura 2 (c). Neste modelo, as vendas passam por vários ciclos de vida baseados na descoberta de novas características do produto, de novos consumidores e de novas utilidades ou aplicações.

Conclui-se que no padrão escalonado, um mesmo produto pode estar presente em diversos ciclos de vida simultaneamente, ou então, o produto pode se renovar e ressurgir a partir de novas possibilidades ao fim de um eventual declínio no desempenho de uma função específica.

Kotler e Keller (2006) abordam ainda três categorias especiais de ciclo de vida do produto: o estilo, a moda e o modismo, conforme a representação da Figura 3.
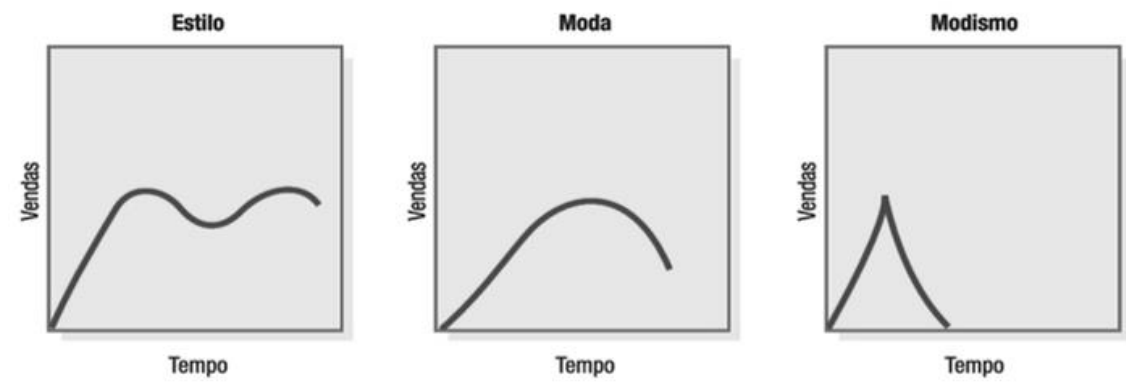

Figura 3. Ciclo de vida de estilo, moda e modismo

Fonte: Kotler e Keller (2006, p. 318).

Segundo Kotler e Keller (2006), o estilo é um modo de expressão básico e diferenciado que pode durar várias gerações, entrando e saindo de moda. Dessa forma, o estilo é caracterizado por um ciclo de vida com diversos períodos de interesse renovado ou com novas fases de introdução.

A moda é um estilo aceito por um determinado período de tempo ou popular em uma determinada área. Em seu estágio de distinção, ela tende a crescer lentamente a partir de sua percepção pelo mercado. Em seguida, ela atinge a sua máxima popularidade, chegando ao estágio de emulação, no qual muitas pessoas desejam aderi-la. Então, a moda permanece popular por um tempo, até atingir o estágio de massificação, período no qual grande parcela do público já a aderiu. Finalmente, inicia-se o estágio de declínio a partir da redução ou desaparecimento da popularidade. (KOTLER; KELLER, 2006)

Por fim, o modismo é a moda que aparece repentinamente e é adotada com grande entusiasmo, atinge rapidamente a maturidade e o consequente declínio. $O$ modismo tende a atrair apenas um pequeno número de adeptos. (KOTLER; KELLER, 2006)

Observa-se que a categoria denominada estilo é análoga ao padrão de ciclo-novo ciclo, pois em ambos as vendas são instáveis. A moda, por sua vez, atinge a popularidade e repentinamente cai em desuso, visto que esta permanece apenas enquanto atender aos atributos requeridos pelo consumidor, e em certo momento este optará por outra moda mais atrativa. Já o modismo, é 
caracterizado por um ciclo de vida curto, podendo se reinventar com o lançamento de novas versões.

\section{CONSIDERAÇÕES FINAIS}

Os processos aqui descritos demonstram a evolução de um produto no mercado, mas nem sempre se adaptam a qualquer produto, pois cada um possui as suas particularidades e a sua trajetória varia de acordo com o mercado em que o mesmo está inserido e com as estratégias desenvolvidas pela organização, sendo assim, um produto não necessariamente passará por todos os estágios ditados pela curva.

Percebe-se que o domínio sobre o conceito de ciclo de vida do produto é importante para o desenvolvimento de um bom planejamento do processo produtivo e da inserção do produto no mercado, sendo necessário entender quais fatores agregam valor ao produto e provocam o interesse do consumidor, e é essencial ainda manter-se competitivo a partir do desenvolvimento de métodos que viabilizem o consumo e não interfiram nos custos de produção, buscando manter uma relação de lealdade com o consumidor.

A reflexão desenvolvida neste artigo permite concluir que os rápidos avanços tecnológicos e as mudanças no mercado exigem da organização uma constante atualização quanto aos métodos e recursos utilizados no processo produtivo, sendo necessária a adoção de novas estratégias a fim de se adaptar e renovar o ciclo de vida de seus produtos.

\section{REFERÊNCIAS}

ASSOCIAÇÃO BRASILEIRA DE ENGENHARIA DE PRODUÇÃO (ABEPRO). Áreas e Sub-áreas de

Engenharia de Produção. Rio de Janeiro, 2008. Disponível em:

<http://www.abepro.org.br/interna.asp?p=399\&m=424\&ss=1\&c=362>. Acesso em: 09 mai. 2015.

CHIAVENATO, Idalberto. Gestão da produção: uma abordagem introdutória. 3. ed. Barueri-SP: Manole, 2014.

KOTLER, Philip; ARMSTRONG, Gary. Princípios de marketing. 15. ed. São Paulo: Pearson Education do Brasil, 2015. Disponível em:

<http://unoeste.bv3.digitalpages.com.br/users/publications/9788543004471/pages/-22>. Acesso em: 06 mai. 2016.

KOTLER, Philip; KELLER, Kevin Lane. Administração de marketing. 12. ed. São Paulo: Pearson Prentice Hall, 2006. Disponível em:

<http://unoeste.bv3.digitalpages.com.br/users/publications/9788576050018/pages/-26>. Acesso em: 06 mai. 2016.

MARTINS, Petrônio Garcia; LAUGENI, Fernando Piero. Administração da produção. São Paulo: Saraiva, 2002.

MOREIRA, Daniel Augusto. Administração da produção e operações. 2. ed. São Paulo: Cengage Learning, 2014.

NAVEIRO, Ricardo Manfredi. Engenharia do Produto. In: BATALHA, Mário Otávio (Org.). Introdução à engenharia de produção. Rio de Janeiro: Elsevier: ABEPRO, 2008, p. 135-156. 